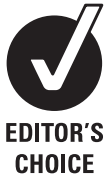

CHOICE

\section{See Editorial, p 285}

${ }^{1}$ Pulmonary Research Institute at Hospital Großhansdorf, Center for Pneumology and Thoracic Surgery, Großhansdorf, Germany

${ }^{2}$ Rabin Medical Center, Beilinson Hospital, Petah Tikva, Tel Aviv, Israel

${ }^{3}$ Service de Pneumologie Hôpital Pasteur-Pavillon $\mathrm{H}$, Centre Hospitalier Universitaire, Nice, France

${ }^{4}$ Department of Respiratory and Critical Care Medicine, Ludwig Boltzmann Institute for COPD, Otto Wagner Hospital, Vienna, Austria

${ }^{5}$ Lungenklinik Hemer, Pneumologie-Thorakale Endoskopie, Hemer, Germany ${ }^{6}$ Zentralklinik Bad Berka GmbH Klinik für Pneumologie, Bad Berka, Germany

'Universitätsklinikum

Bergmannsheil $\mathrm{GmbH}$,

Medizinische Klinik III für

Pneumologie, Allergologie,

Schlaf- und Beatmungsmedizin,

Bochum, Germany

${ }^{8}$ Division of Thoracic Surgery,

Saroka Medical Center, Be'er

Sheva, Israel

${ }^{9}$ Thoraxklinik am

Universitätsklinikum Heidelberg, Heidelberg, Germany

\section{Correspondence to}

Professor Helgo Magnussen, Pulmonary Research Institute at Hospital Großhansdorf, Center for Pneumology and Thoracic Surgery, Großhansdorf, Großhansdorf 22927, Germany: magnussen@pulmoresearch.de

Received 1 September 2011 Accepted 9 December 2011 Published Online First 28 February 2012

\title{
Effect of fissure integrity on lung volume reduction using a polymer sealant* in advanced emphysema
}

Helgo Magnussen, ${ }^{1}$ Mordechai R Kramer, ${ }^{2}$ Anne-Marie Kirsten, ${ }^{1}$ Charles Marquette, ${ }^{3}$ Arschang Valipour, ${ }^{4}$ Franz Stanzel, ${ }^{5}$ Reiner Bonnet, ${ }^{6}$ Juergen Behr, ${ }^{7}$ Oren Fruchter, ${ }^{2}$ Yael Refaely, ${ }^{8}$ Ralf Eberhardt, ${ }^{9}$ Felix J F Herth ${ }^{9}$

\section{ABSTRACT}

Rationale Interlobar fissure integrity has previously correlated with responsiveness to endobronchial lung volume reduction therapy in patients with advanced emphysema.

Objective This report summarises the effect of interlobar fissure integrity on responses to treatment with a novel endoscopic tissue sealant (AeriSeal emphysematous lung sealant (ELS)) that collapses hyperinflated lung.

Methods Fissure status, lung volumes, tissue density and disease heterogeneity were assessed radiographically in 28 patients (age $63.4 \pm 6.1$ years, 20 men) with advanced upper lobe predominant emphysema (density=888.0 $\pm 18.2 \mathrm{HU}$; upper lobe tissue density $<-950=2.62 \pm 1.74$ ). Post-treatment changes in lobar volume, pulmonary function, exercise capacity, symptoms and quality of life were compared in patients with complete fissures (CFs) and incomplete fissures (ICFs).

Results ELS therapy reduced lung volumes independent of interlobar fissure integrity. In patients with upper lobe emphysema and $\mathrm{CFs}$, lobar volume reduction was $214 \pm 127 \mathrm{ml} /$ treatment compared with $256 \pm 175 \mathrm{ml} /$ treatment in those with ICFs $(p=0.453)$. Reductions in gas trapping and improvements in spirometry, functional capacity and quality of life were similar in patients with CFs and ICFs. Stepwise multiple regression modelling confirmed that fissure integrity did not contribute to post-treatment changes in forced expiratory volume in $1 \mathrm{~s}$, residual volume/total lung capacity ratio or lobar volume measured by CT analysis.

Conclusions Interlobar fissure integrity, an important determinant of responsiveness to endobronchial lung volume reduction therapy in prior studies, had minimal impact on physiological and functional responses to ELS therapy in patients with severe upper lobe predominant emphysema.

Clinical trial registration number Registration numbers for trials contributing to datasets in this report: NCT00884962, NCT01051258 and NCT01181466.

\section{INTRODUCTION}

Hyperinflation is a cardinal feature of pulmonary emphysema and an important determinant of airflow obstruction, exercise limitation and dyspnoea. ${ }^{1}{ }^{2}$ Lung volume reduction (LVR) therapy reduces hyperinflation by eliminating diseased lung that contributes to gas trapping. Surgical LVR has traditionally been the standard of care, and while

\section{Key messages}

What is the key question?

- Can endoscopic lung volume reduction therapy effectively treat patients with emphysema who have incomplete fissures by $\mathrm{CT}$ imaging?

\section{What is the bottom line?}

- In contrast to endobronchial valves, which are ineffective for treating patients with emphysema with incomplete interlobar fissures, endoscopic lung sealant therapy produces equivalent lung volume reduction, improvements in spirometry and improvements in patient-reported outcomes in patients with complete and incomplete fissures.

\section{Why read on?}

- This article confirms that endoscopic lung volume reduction therapy using a peripheral acting sealant can consistently improve physiology and function in patients with advanced emphysema independent of interlobar fissure integrity, indicating that this approach may have broad therapeutic applicability for patients with advanced emphysema refractory to medications.

effective, is associated with significant acute and subacute morbidity and mortality. ${ }^{3} 4$ For this reason, it is now rarely performed. Endobronchial methods for achieving LVR, ${ }^{6}{ }^{6}$ while safer than surgical LVR, do not consistently reduce hyperinflation or improve lung function, and thus have not had a significant clinical impact on the management of patients with emphysema.

Variability in response to endobronchial LVR has largely been attributed to collateral ventilation, the process whereby gas enters the lung periphery through parallel channels in the diseased tissue. This renders devices, such as endobronchial valves, ineffective. ${ }^{7}$ Interlobar fissure integrity has been correlated with the efficacy of endobronchial valves and is believed to be a marker of collateral ventilation. AeriSeal (Aeris Therapeutics, Woburn, MA USA) emphysematous lung sealant (ELS) is a liquid foam sealant that functions at the small airway and alveolar level, and is designed to produce volume reduction independent of collateral ventilation. ${ }^{8}$ This article summarises the effects of ELS therapy on lobar and total lung volumes, gas trapping, 
spirometry, functional capacity and health-related quality of life in patients with advanced upper lobe predominant (ULP) heterogeneous emphysema with and without complete fissures (CFs).

\section{MATERIALS AND METHODS Source of data}

Results from patients with advanced ULP emphysema (Global Initiative for Chronic Obstructive Lung Disease (GOLD) stage III or IV obstruction) in three clinical trials using AeriSeal ELS therapy (NCT00884962, NCT01051258 and NCT01181466) are included in this report. ${ }^{8}$ The studies were open-label, multicentre trials conducted at six teaching hospitals in Germany, one in France, one in Austria and two in Israel. Patient inclusion and exclusion criteria, which were common across the studies, are listed on the website (http://www.clinicaltrials.gov).

\section{Assessments}

Screening assessments included pulmonary function tests (spirometry, plethysmography and single breath diffusing capacity), 6 min walk test (6MWT), electrocardiography, chest CT scan performed at full inspiration, clinical pathology (haematology, coagulation studies and serum chemistry measurements), modified Medical Research Council Dyspnoea (MRCD) questionnaire, and St George's Respiratory Questionnaire (SGRQ) health-related quality of life assessment. Outcomes and CT imaging were repeated at 3 months post treatment. All CT images were obtained using a standardised acquisition/reconstruction algorithm (spiral acquisition using a multi-detector CT scanner with $0.75-1 \mathrm{~mm}$ collimation, pitch of 1 and $0.5 \mathrm{~mm}$ overlap).

Patients were classified as having ULP heterogeneous emphysema based on visual CT assessments by investigators in conjunction with their radiology departments. Treatment sites were selected based on CT imaging. Computer-based analysis of dicom images (see below) by the study Sponsor Corelab was performed independently for research purposes to assess fissure integrity and measure regional and global patterns of LVR following therapy.

\section{CT analysis}

Quantitative image analysis was performed using commercially available software using dicom source images (VIDA Diagnostics Pulmonary Workstation Plus Software, Iowa City, Iowa, USA). Fissure integrity was assessed using sagittal and coronal CT scan isotropic reconstructions. The major fissure on the left, the major fissure on the right and the minor fissure on the right were evaluated independently. A fissure was designated as incomplete if $10 \%$ or more of its measured length could not be identified on at least three consecutive $0.6 \mathrm{~mm}$ slices. Reviews were performed independently by two experienced readers. In instances where initial reads were not concordant, the two reviewers analysed the scan together to reach consensus. Fissures were scored as either complete or incomplete. Lobes were determined to have CFs only if all adjacent interlobar fissures were complete.

\section{Data presentation and statistical analysis}

Outcome measures post treatment were compared with baseline values and reported as absolute and/or percentage change from baseline. Descriptive statistics were presented as either mean $\pm \mathrm{SD}$ (for datasets demonstrating a normal distribution pattern) or median and range as appropriate. Statistical significance of changes from baseline and between subgroups was assessed by Student $t$ test, paired $t$ test or non-parametric testing (Wilcoxon signed rank for paired data, Mann-Whitney $U$ test for unpaired data). Comparisons of categorical data were performed by chi-squared testing. Statistical significance was based on $p$ values subject to correction for multiple comparisons using the method of Bonferroni.

Multiple regression analysis was performed to identify independent predictors of improvement in forced expiratory volume in $1 \mathrm{~s}\left(\mathrm{FEV}_{1}\right)$ and reduction in lung volume. Univariate regression between putative independent variables and each dependent variable (ie, $\Delta \mathrm{FEV}_{1}, \Delta$ residual volume $(\mathrm{RV}) /$ total lung capacity (TL) and change in lobar lung volume assessed by CT scan) was first performed, and independent variables demonstrating statistically significant relations to each dependent variable were included in the multiple regression model. Fissure integrity status was specifically included in each regression model to assess its effect on dependent outcome measures.

\section{RESULTS}

Baseline demographics, medical history and pulmonary function A total of 54 patients with ULP heterogeneous emphysema were enrolled in the three clinical trials. Complete follow-up data were available for 48 patients. Twenty-eight of the 48 (58\%) had correctly formatted CT images at baseline and follow-up, permitting isotropic or near isotropic reconstruction for lobar volume assessments. The results from all 28 patients are included in this article.

Demographic information and baseline medication usage are summarised in table 1 . The characteristics of all 54 patients are compared with those included in this analysis. Baseline characteristics are similar with respect to age, gender distribution, medication use and disease severity, indicating that the 28patient subgroup is representative of the entire study cohort. Seventeen of the 28 patients had GOLD stage III airflow obstruction; 11 had GOLD stage IV. The majority (20 patients) were men. One patient used non-invasive facemask ventilation at home. Five patients were listed for lung transplantation at the time of study enrolment. One patient had previously undergone a pleurodesis procedure for pneumothorax. All 28 patients were using $\beta$-agonist therapy (14 short acting, 28 long acting), 25 patients were using inhaled anticholinergic agents (9 short acting, 24 long acting), 23 patients inhaled corticosteroid preparations, 7 theophylline preparations, 4 oral corticosteroids and 8 mucolytics. Nine patients were receiving domiciliary oxygen therapy.

Patients were treated at two to four subsegmental sites over one or two treatment sessions. Patients were assigned to the CF treatment subgroup if they received one or more treatments in a lobe with a CF. Only patients who received all treatments in lobes with incomplete fissures (ICFs) were assigned to the CF subgroup.

Baseline physiological and functional characteristics for all 54 enrolled patients and for the subgroup with evaluable data $(n=28)$ are summarised in table 2 . Profiles are consistent with advanced emphysema, showing severe airflow obstruction, hyperinflation and functional limitation with reduced exercise capacity. Thirteen patients were assigned to the CF subgroup and 15 were assigned to the ICF subgroup. Comparison of the CF and ICF subgroups showed a significant difference in baseline forced vital capacity (FVC), although baseline \% predicted FVC was not different. Patients with ICFs were older than those with CFs $(66.3 \pm 5.4$ years vs $60.1 \pm 5.1$ years, respectively; $p=0.003)$. The two subgroups were not different with respect to smoking history, gender distribution, proportion of GOLD stage III versus IV patients, body mass index or medication use. 
Table 1 Patients' demographics and medical therapy

\begin{tabular}{llllll}
\hline & $\begin{array}{l}\text { All patients } \\
\text { with ULP }\end{array}$ & $\begin{array}{l}\text { Complete and } \\
\text { incomplete }\end{array}$ & $\begin{array}{l}\text { Complete } \\
\text { fissure }\end{array}$ & $\begin{array}{l}\text { Incomplete } \\
\text { fissure }\end{array}$ & $\begin{array}{l}\text { Complete vs } \\
\text { incomplete } \\
\text { p value* }\end{array}$ \\
\hline $\begin{array}{l}\text { Demographics } \\
\quad\end{array}$ & 54 & 28 & 13 & 15 & - \\
$\quad$ No. patients & $37(69)$ & $20(71)$ & $6(46)$ & $14(93)$ & $0.013 \dagger$ \\
$\quad$ No. men (\%) & $28 / 26$ & $17 / 11$ & $10 / 3$ & $8 / 8$ & $0.271 \dagger$ \\
GOLD stage III/IV & $51(10$ to 160$)$ & $48(10$ to 160$)$ & $43(10$ to 90$)$ & $59(30$ to 160$)$ & $0.068 \neq$ \\
Smoking (packet years), median & & & & & \\
(range) & $62.9 \pm 7.2$ & $63.3 \pm 6.0$ & $60.1 \pm 5.1$ & $66.1 \pm 5.3$ & 0.003 \\
Age (years) & $24.1 \pm 4.3$ & $24.4 \pm 4.6$ & $23.5 \pm 4.5$ & $24.8 \pm 4.8$ & 0.660 \\
BMI (kg/m²) & & & & & \\
Medication, n (\%) & $28(51)$ & $14(50)$ & $8(62)$ & $6(40)$ & 0.449 \\
SABA & $54(100)$ & $28(100)$ & $13(100)$ & $15(100)$ & 1.0 \\
LABA & $18(33)$ & $9(32)$ & $5(38)$ & $4(27)$ & 0.793 \\
SAAC & $51(94)$ & $24(86)$ & $11(85)$ & $13(87)$ & 1.0 \\
LAAC & $46(85)$ & $23(82)$ & $11(85)$ & $12(80)$ & 1.0 \\
ICS & $11(20)$ & $7(25)$ & $2(15)$ & $5(33)$ & 0.516 \\
Theophylline & $9(17)$ & $4(14)$ & $2(15)$ & $2(13)$ & 1.0 \\
Oral steroids & $22(41)$ & $9(32)$ & $4(30)$ & $5(33)$ & 1.0 \\
Oxygen use (any) &
\end{tabular}

*Significance defined as $\mathrm{p}=0.008$ when corrected for multiple comparisons.

†Comparison complete versus incomplete by chi-squared test with Yates correction.

$\ddagger$ Comparison complete versus incomplete via Mann-Whitney non-parametric test.

BMI, body mass index; GOLD, Global Initiative for Chronic Obstructive Lung Disease; ICS, inhaled corticosteroid; LAAC, long-acting anticholinergic agents; LABA, long-acting $\beta$-agonist; SAAC, short-acting anticholinergic agent; SABA, short-acting $\beta$-agonist; ULP, upper lobe predominant.

\section{Summary of overall physiological and functional outcomes}

The average number of sites treated per patient was $2.9 \pm 0.9$. There was no difference in the number of treatment sites between subgroups ( $\mathrm{CF}=3.2 \pm 1.0$ sites vs $\mathrm{ICF}=2.6 \pm 0.9$ sites). Efficacy outcomes following ELS therapy are summarised in table 3. Mean responses, expressed as percentage change and/or absolute change from baseline, and the fraction of patients showing post-treatment improvements equal to or greater than established minimal clinical importance difference criteria are presented. ${ }^{10}$ Significant improvements from baseline were observed for all outcome measures when corrected for multiple comparisons ( $p_{\text {significant }}$ $=0.008$ ). Improvements at 12 -week follow-up were observed in spirometry $\left(\Delta \mathrm{FEV}_{1}=19.1 \pm 21.5 \%, \mathrm{p}<0.001 ; \Delta \mathrm{FVC}=11.2 \pm 17.1 \%\right.$, $\mathrm{p}=0.003)$, gas trapping $(\Delta \mathrm{RV} / \mathrm{TLC}=-6.5 \pm 10.7 \%, \mathrm{p}=0.007)$, exercise capacity $(\Delta 6 \mathrm{MWT}=30.9 \pm 50.2 \mathrm{~m}, \mathrm{p}=0.005)$, symptoms $(\Delta \mathrm{MRCD}=-0.89 \pm 1.09 \mathrm{U}, \mathrm{p}=0.004)$ and health-related quality of life $(\Delta S G R Q=-11.6 \pm 12.4, \quad \mathrm{p}<0.001)$. Clinically significant improvements in spirometry were observed in $64 \%$ of patients, dyspnoea in $55 \%$ of patients, and health-related quality of life in
$71 \%$ of patients. Patients with CFs and ICFs responded equally well to therapy. There were no significant differences between the two subgroups in any outcome measures.

\section{Radiological characterisation of study patients}

The heterogeneity index (HI) for the study cohort, defined as the ratio of the percentage of voxels with a density $<-950$ Hounsfield unit (HU) in the upper lobes (right upper + left upper) to that in the lower lobes (right lower + left lower), was $2.62 \pm 1.74$ (range 0.87-8.49). CT assessments of disease severity, expressed as lung tissue density and percentage of low attenu-

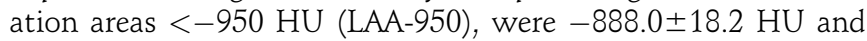
$31.4 \pm 12.3 \%$, respectively. CT indices of disease severity at baseline were similar in CF and ICF subgroups (tissue density: $\mathrm{CF}=-889.1 \pm 24.8 \mathrm{HU}$ vs ICF $=-887.0 \pm 10.7 \mathrm{HU}, \mathrm{p}=0.754$; and LAA-950: $\quad C F=34.9 \pm 13.4 \% \quad$ vs $\quad I C F=28.4 \pm 10.7 \%, \quad p=0.169)$. Eighty per cent of patients had CT evidence of at least one ICF (most frequently the minor fissure on the right). Bilateral ICFs were observed in $31 \%$ of patients.

Table 2 Baseline patient characteristics

\begin{tabular}{|c|c|c|c|c|c|}
\hline & \multicolumn{5}{|c|}{ Baseline physiological and functional measures } \\
\hline & All patients $(n=54)$ & Patients with full datasets $(n=28)$ & Complete fissures $(n=13)$ & Incomplete fissures $(n=15)$ & $\begin{array}{c}\text { Difference } \\
\text { p value* }\end{array}$ \\
\hline $\mathrm{FEV}_{1}$, litres & $0.92 \pm 0.32(30.4 \pm 8.2 \%$ pred $)$ & $1.02 \pm 0.35(33.0 \pm 8.3 \%$ pred $)$ & $\begin{array}{l}0.98 \pm 0.40(33.0 \pm 9.0 \% \text { pred }) \\
\text { range } 0.48 \text { to } 1.42\end{array}$ & $\begin{array}{l}1.05 \pm 0.29(33.1 \pm 7.7 \% \text { pred }) \\
\text { range } 0.67 \text { to } 1.72\end{array}$ & 0.443 \\
\hline FVC, litres & $2.63 \pm 0.74(64.1 \pm 13.2 \%$ pred $)$ & $2.68 \pm 0.71(66.0 \pm 12.5 \%$ pred $)$ & $\begin{array}{l}2.36 \pm 0.78(61.2 \pm 13.7 \% \text { pred }) \\
\text { range } 1.33 \text { to } 4.03\end{array}$ & $\begin{array}{l}2.94 \pm 0.39(70.4 \pm 10.5 \% \text { pred }) \\
\text { range } 2.25 \text { to } 4.41\end{array}$ & 0.008 \\
\hline RV, litres & $5.52 \pm 1.23(242.4 \pm 62.3 \%$ pred $)$ & $5.02 \pm 0.84(227.0 \pm 50.3 \%$ pred $)$ & $\begin{array}{l}5.42 \pm 0.87(259.3 \pm 37.0 \% \text { pred }) \\
\text { range } 3.66 \text { to } 6.39\end{array}$ & $\begin{array}{l}4.76 \pm 0.65(202.3 \pm 45.9 \% \text { pred }) \\
\text { range } 3.72 \text { to } 6.14\end{array}$ & 0.035 \\
\hline MRCD, U & $2.90 \pm 0.74$ & $2.93 \pm 0.75$ & $\begin{array}{l}3.1 \pm 0.76 \\
\text { range } 2.0 \text { to } 4.0\end{array}$ & $\begin{array}{l}2.8 \pm 0.74 \\
\text { range } 2.0 \text { to } 4.0\end{array}$ & 0.291 \\
\hline 6MWT, m & $309.0 \pm 89.9$ & $328 \pm 90$ & $\begin{array}{l}292 \pm 90 \\
\text { range } 160 \text { to } 420\end{array}$ & $\begin{array}{l}347 \pm 75 \\
\text { range } 216 \text { to } 529\end{array}$ & 0.057 \\
\hline
\end{tabular}

*Comparison of patients with complete versus incomplete fissures performed by Student t test; significance defined as $p \leq 0.008$ when corrected for multiple comparisons.

6MWT, 6 min walk test; FEV , forced expiratory volume in 1 s; FVC, forced vital capacity; MRCD, Medical Research Council Dyspnoea; pred, predicted; RV, residual volume; TLC, total lung capacity. 
Table 3 Response to emphysematous lung sealant therapy at week 12

\begin{tabular}{|c|c|c|c|c|}
\hline & Entire cohort, ${ }^{*} n=28$ & Complete fissure, ${ }^{*} n=13$ & Incomplete fissure, ${ }^{*} n=15$ & $\begin{array}{l}\text { Difference in CF } \\
\text { vs ICF } p \text { value } \dagger\end{array}$ \\
\hline$\Delta \mathrm{FEV}_{1}$ & $\begin{array}{l}19.1 \pm 21.5 \%(0.18 \pm 0.22 \text { litres }) \\
\mathrm{p}<0.001 \text { vs baseline } \neq \\
55 \% \text { responders } \S\end{array}$ & $\begin{array}{l}20.6 \pm 23.3 \%(0.19 \pm 0.26 \text { litres }) \\
\text { range }-12 \text { to }+68 \%\end{array}$ & $\begin{array}{l}17.7 \pm 20.5 \%(0.15 \pm 0.19 \text { litres }) \\
\text { range }-3.0 \text { to }+68 \%\end{array}$ & 0.717 \\
\hline$\Delta \mathrm{FVC}$ & $\begin{array}{l}11.2 \pm 17.1 \%(0.25 \pm 0.48 \text { litres }) \\
p=0.003 \text { vs baseline } \neq \\
41 \% \text { responders } \S\end{array}$ & $\begin{array}{l}14.6 \pm 22.7 \%(0.29 \pm 0.50 \text { litres }) \\
\text { range }-16.4 \text { to }+55.4 \%\end{array}$ & $\begin{array}{l}9.3 \pm 17.4 \%(0.21 \pm 0.47 \text { litres }) \\
\text { range }-24.5 \text { to }+27.4 \%\end{array}$ & 0.311 \\
\hline$\Delta \mathrm{RV} / \mathrm{TLC}$ & $\begin{array}{l}-6.5 \pm 10.7 \% \\
p=0.007 \text { vs baseline } \neq\end{array}$ & $\begin{array}{l}-9.1 \pm 10.0 \% \\
\text { range }-22.9 \text { to }+4.4 \%\end{array}$ & $\begin{array}{l}-4.1 \pm 11.1 \% \\
\text { range }-25.4 \text { to }+16.8 \%\end{array}$ & 0.191 \\
\hline$\Delta R V$ & $\begin{array}{l}-9.3 \pm 15.8 \%(-0.51 \pm 0.81 \text { litres }) \\
p<0.001 \text { vs baseline } \neq\end{array}$ & $\begin{array}{l}-13.0 \pm 14.2 \%(-0.70 \pm 0.75 \text { litres }) \\
\text { range }-33.1 \text { to }+10.4 \%\end{array}$ & $\begin{array}{l}-5.5 \pm 17.0 \%(-0.31 \pm 0.86 \text { litres }) \\
\text { range }-36.0 \text { to }+24.1 \%\end{array}$ & 0.215 \\
\hline$\Delta \mathrm{TLC}$ & $\begin{array}{l}-2.6 \pm 8.8 \%(-0.73 \pm 1.90 \text { litres }) \\
p<0.001 \text { vs baseline } \neq\end{array}$ & $\begin{array}{l}-4.1 \pm 7.8 \%(-0.32 \pm 66 \text { litres }) \\
\text { range }-14.7 \text { to }+11.1 \%\end{array}$ & $\begin{array}{l}-1.1 \pm 9.7 \%(-0.10 \pm 0.79 \text { litres }) \\
\text { range }-23.8 \text { to }+11.7 \%\end{array}$ & 0.422 \\
\hline$\triangle \mathrm{MRCD}$ & $\begin{array}{l}-0.89 \pm 1.09 \mathrm{U} \\
\mathrm{p}=0.004 \text { vs baseline } \neq \\
55 \% \text { responders } \S\end{array}$ & $\begin{array}{l}-1.23 \pm 1.30 \mathrm{U} \\
\text { range }-3.0 \text { to } 1.0\end{array}$ & $\begin{array}{l}-0.67 \pm 0.76 \mathrm{U} \\
\text { range }-2.0 \text { to } 1.0\end{array}$ & 0.407 \\
\hline$\Delta 6 \mathrm{MWT}$ & $\begin{array}{l}30.9 \pm 50.2 \mathrm{~m} \\
\mathrm{p}=0.005 \text { vs baseline } \neq \\
31 \% \text { responders } \S\end{array}$ & $\begin{array}{l}36.7 \pm 49.0 \mathrm{~m} \\
\text { range }-59 \text { to } 127\end{array}$ & $\begin{array}{l}27.3 \pm 52.5 \mathrm{~m} \\
\text { range }-70 \text { to } 130\end{array}$ & 0.781 \\
\hline$\Delta \mathrm{SGRO}$ & $\begin{array}{l}-11.6 \pm 12.4 \mathrm{U} \\
\mathrm{p}<0.001 \text { vs baseline } \neq \\
71 \% \text { responders } \S\end{array}$ & $\begin{array}{l}-13.6 \mathrm{U} \\
\text { range }-37.4 \text { to } 8.1\end{array}$ & $\begin{array}{l}-9.8 \mathrm{U} \\
\text { range }-33.9 \text { to } 8.5\end{array}$ & 0.427 \\
\hline
\end{tabular}

*Data normally distributed, presented as mean $\pm \mathrm{SD}$.

†Comparison of CFs and ICFs via Student $t$ test; significance defined as $p \leq 0.008$ when corrected for multiple comparison.

$\ddagger$ Comparison by paired $t$ test.

SResponder definitions: $\triangle \mathrm{FEV}_{1}$ and FVC $\geq+12 \% ; \triangle \mathrm{MRCD} \leq-1 \mathrm{U} ; \Delta 6 \mathrm{MWT} \geq 54 \mathrm{~m} ; \Delta \mathrm{SGRO} \leq-4 \mathrm{U}$.

6MWT, 6 min walk test; $\mathrm{CF}$, complete fissure; $\mathrm{FEV}_{1}$, forced expiratory volume in $1 \mathrm{~s}$; FVC, forced vital capacity; ICF, incomplete fissure. MRCD, Medical Research Council Dyspnoea; RV, residual volume; SGRO, St George's Respiratory Questionnaire; TLC, total lung capacity.

\section{Impact of fissure integrity on response to ELS therapy}

The average volume reduction/treatment was $-214 \pm 127 \mathrm{ml}$ $(\mathrm{p}<0.0001$ vs baseline; median $-203 \mathrm{ml}$, range -6 to $-417 \mathrm{ml})$ in the CF subgroup compared with $-256 \pm 175 \mathrm{ml}(\mathrm{p}<0.0001 \mathrm{vs}$ baseline; median $-261 \mathrm{ml}$, range -59 to $-636 \mathrm{ml}$ ) in the ICF subgroup ( $\mathrm{p}=0.453$ ).

Physiological and functional responses to ELS therapy in patients with CFs and ICFs are summarised in table 3. Changes from baseline in $\mathrm{FEV}_{1}$, FVC, RV/TLC, 6MWT distance, MRCD score and SGRQ total domain scores following ELS therapy were not significantly different between the two groups.

Potential effects of fissure integrity on response to ELS therapy were further assessed across the cohort using stepwise multiple regression analysis. Changes from baseline in $\mathrm{FEV}_{1}, \mathrm{RV} / \mathrm{TLC}$ and CT volume reduction were analysed separately as dependent outcomes. Independent parameters considered for inclusion in the multivariate modelling, and subsequently incorporated into the model dependent upon univariate regression results, included baseline $\mathrm{HI}$, baseline CT severity score, baseline \% predicted $\mathrm{FEV}_{1}$, baseline \% predicted RV, baseline RV/TLC, age, number of sites treated and fissure integrity status. The results are summarised in table 4. Baseline HI, number of treatments administered, baseline $\%$ predicted $\mathrm{RV}$ and patient age were predictors of $\mathrm{FEV}_{1}$ response according to the following relationship: $\Delta \mathrm{FEV}_{1}=17.1+0.077 \times$ $\%$ predicted baseline RV $-0.612 \times$ age $+2.292 \times$ number of treatments $+5.253 \times \mathrm{U} / \mathrm{L}$ ratio $(\mathrm{p}=0.0317)$. The number of treatments administered was the only predictor of change from baseline in RV/TLC $(\Delta \mathrm{RV} / \mathrm{TLC}=-0.010-1.554 \times$ number of treatments; $p=0.047$ ) and change from baseline in CT lung volume $(\Delta C T$ reduction $=-201.5-119.4 \times$ number of treatments; $\mathrm{p}=0.0001)$. Fissure integrity was not an independent predictor of response in any of the regression models, and therefore did not influence ELS effects on spirometry, gas trapping or lobar volume reduction.

\section{DISCUSSION}

The presence of intact interlobar fissures, assessed by CT imaging, is a characteristic of patients with emphysema who respond well to LVR therapy performed using endobronchial valves. ${ }^{11}$ Conversely, patients with ICFs have not responded well to valve therapy, presumably due to the presence of collateral ventilation. ${ }^{12} 13$ Newer endoscopic volume reduction techniques have been developed to function independently of collateral ventilation. $^{8}{ }^{914-16}$ One such therapy, AeriSeal ELS therapy, is designed to produce absorption atelectasis by flowing into the lung periphery and blocking conducting airways and collateral ventilation channels. The present analysis was performed to characterise the effectiveness of ELS therapy in patients with CFs and ICFs, and assess the relationship between fissure integrity and response to therapy in patients with advanced ULP heterogeneous emphysema.

Among the 28 patients included in this study, over threequarters had at least one ICF. Despite this, overall responses to ELS therapy were favourable. A total of $64 \%$ (18 of 28) of patients experienced clinically significant improvements in spirometry ( $>12 \%$ improvement in $\mathrm{FEV}_{1}$ and/or $\mathrm{FVC}$ ), and $71 \%$ (20 of 28) experienced improvements in health-related quality of life ( $\geq 4$ unit reduction in SGRO total domain score) at 12 weeks. Improvement in pulmonary function was observed more consistently in patients who received treatment at three (75\%, 3 of 4 patients) and four subsegments (70\%, 7 of 10 patients) versus those treated at only two subsegments (43\%, 6 of 14 patients). These results, along with the results of multivariate regression modelling, confirm a dose-response relationship for therapy.

ELS therapy was nearly equally effective in CF and ICF subgroups. At 12-week follow-up, lobar volume reductions, and improvements in spirometry, gas trapping and patient-reported outcomes, were not significantly different among patients with CFs and those with ICFs. Although there was a difference in age and gender distribution between the two subgroups (patients with ICFs were significantly older and included a greater proportion of men), patients were otherwise similar demographically (table 1) and physiologically (table 2) at baseline. CT measures of disease severity and heterogeneity, baseline pulmonary function, exercise capacity and dyspnoea scores were also similar. 
Table 4 Multivariate regression analysis tables

\begin{tabular}{|l|c|c|c|c|}
\hline \multicolumn{1}{|c|}{ FEV $_{\mathbf{1}}$} & \multicolumn{5}{|c|}{ Additional variation explained after step } \\
\hline Explanatory variable & $\mathbf{0}$ & $\mathbf{1}$ & $\mathbf{2}$ & $\mathbf{3}$ \\
\hline Hetero Index (HI) & $21.8 \%$ & - & - & - \\
\hline Severity score & $9.1 \%$ & $0.0 \%$ & $-0.1 \%$ & $0.1 \%$ \\
\hline Base \% pred FEV 1 & $2.8 \%$ & $0.4 \%$ & $0.0 \%$ & $0.1 \%$ \\
\hline Base \% pred RV & $0.1 \%$ & $5.3 \%$ & $4.6 \%$ & $2.5 \%$ \\
\hline Baseline RV/TLC & $1.0 \%$ & $0.9 \%$ & $1.1 \%$ & $0.1 \%$ \\
\hline Age & $2.5 \%$ & $4.9 \%$ & $4.7 \%$ & - \\
\hline Number of treatments & $20.1 \%$ & $6.7 \%$ & - & - \\
\hline Fissure integrity & $0.5 \%$ & $0.5 \%$ & $0.0 \%$ & $0.1 \%$ \\
\hline p Value of model & 0.0122 & 0.0152 & 0.0195 & 0.0317 \\
\hline
\end{tabular}

Dependent variable FEV $_{1}$

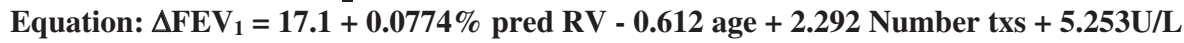
ratio

Effect estimate: Model explains $35.7 \%$ of the variance in $\mathrm{FEV}_{1}$ associated with ELS treatment 95\% CIs for model coefficients:

$$
\begin{array}{ll}
\text { Intercept } & =-81.3 \text { to } 112.4 \\
\text { \%pred RV } & =-0.16 \text { to } 0.19 \\
\text { Age } & =-1.9 \text { to } 0.85 \\
\text { Number txs } & =0.73 \text { to } 6.6 \\
\text { U/L Ratio } & =1.37 \text { to } 9.19
\end{array}
$$

\begin{tabular}{|l|c|c|}
\hline \multicolumn{1}{|c|}{$\Delta \mathbf{R V} / \mathbf{T L C}$} & \multicolumn{2}{c|}{ Additional variation explained after step } \\
\hline Explanatory variable & $\mathbf{0}$ & $\mathbf{1}$ \\
\hline Hetero Index (HI) & $1.5 \%$ & $0.5 \%$ \\
\hline Severity score & $0.1 \%$ & $1.2 \%$ \\
\hline Base $\%$ pred FEV $_{1}$ & $0.0 \%$ & $0.1 \%$ \\
\hline Base \% pred RV & $0.6 \%$ & $1.2 \%$ \\
\hline Baseline RV/TLC & $0.8 \%$ & $3.2 \%$ \\
\hline Age & $0.5 \%$ & $0.3 \%$ \\
\hline Number of treatments & $14.8 \%$ & - \\
\hline Fissure integrity & $5.5 \%$ & $3.5 \%$ \\
\hline p Value of model & 0.047 & 0.088 \\
\hline
\end{tabular}

\section{Dependent variable: $\triangle R$ V/TLC}

\section{Equation: $\triangle \mathrm{RV} / \mathrm{TLC}=\mathbf{- \mathbf { 0 . 0 1 0 }} \mathbf{- 1 . 5 5 4}$ Number txs}

Effect estimate: Model explains $14.8 \%$ of variance in gas trapping (RV/TLC) associated with ELS treatment

95\% CIs for model coefficients:

$$
\begin{array}{ll}
\text { Intercept } & =-7.56 \text { to } 7.36 \\
\text { Number txs } & =-3.09 \text { to }-0.21
\end{array}
$$

\begin{tabular}{|l|c|c|}
\hline \multicolumn{1}{|c|}{ CT reduction } & \multicolumn{2}{|c|}{ Additional variation explained after step } \\
\hline Explanatory variable & $\mathbf{0}$ & $\mathbf{1}$ \\
\hline Hetero Index (HI) & $15.0 \%$ & $0.6 \%$ \\
\hline Severity score & $0.1 \%$ & $3.9 \%$ \\
\hline Base \% pred FEV1 & $0.3 \%$ & $1.9 \%$ \\
\hline Base \% pred RV & $0.2 \%$ & $1.7 \%$ \\
\hline Baseline RV/TLC & $0.3 \%$ & $1.0 \%$ \\
\hline Age & $0.4 \%$ & $1.0 \%$ \\
\hline Number of treatments & $44.1 \%$ & - \\
\hline Fissure integrity & $0.5 \%$ & $0.1 \%$ \\
\hline p Value & 0.0001 & 0.0005
\end{tabular}

Dependent variable: CT Volume reduction

Equation: $\Delta$ CT Lung volume = -201.5 - 119.4 Number txs

Effect estimate: Model explains $44.1 \%$ of variance in lobar CT volume reduction associated with ELS treatment.

95\% CIs for model coefficients:

$$
\begin{array}{ll}
\text { Intercept } & =-461.2 \text { to } 68.3 \\
\text { Number txs } & =-174.6 \text { to }-65.2
\end{array}
$$


Figure 1 CT images at baseline and 12 weeks following emphysematous lung sealant therapy for patients with complete (left panels) and incomplete (right panels) fissures. LUL, left upper lobe; RUL, right upper lobe.

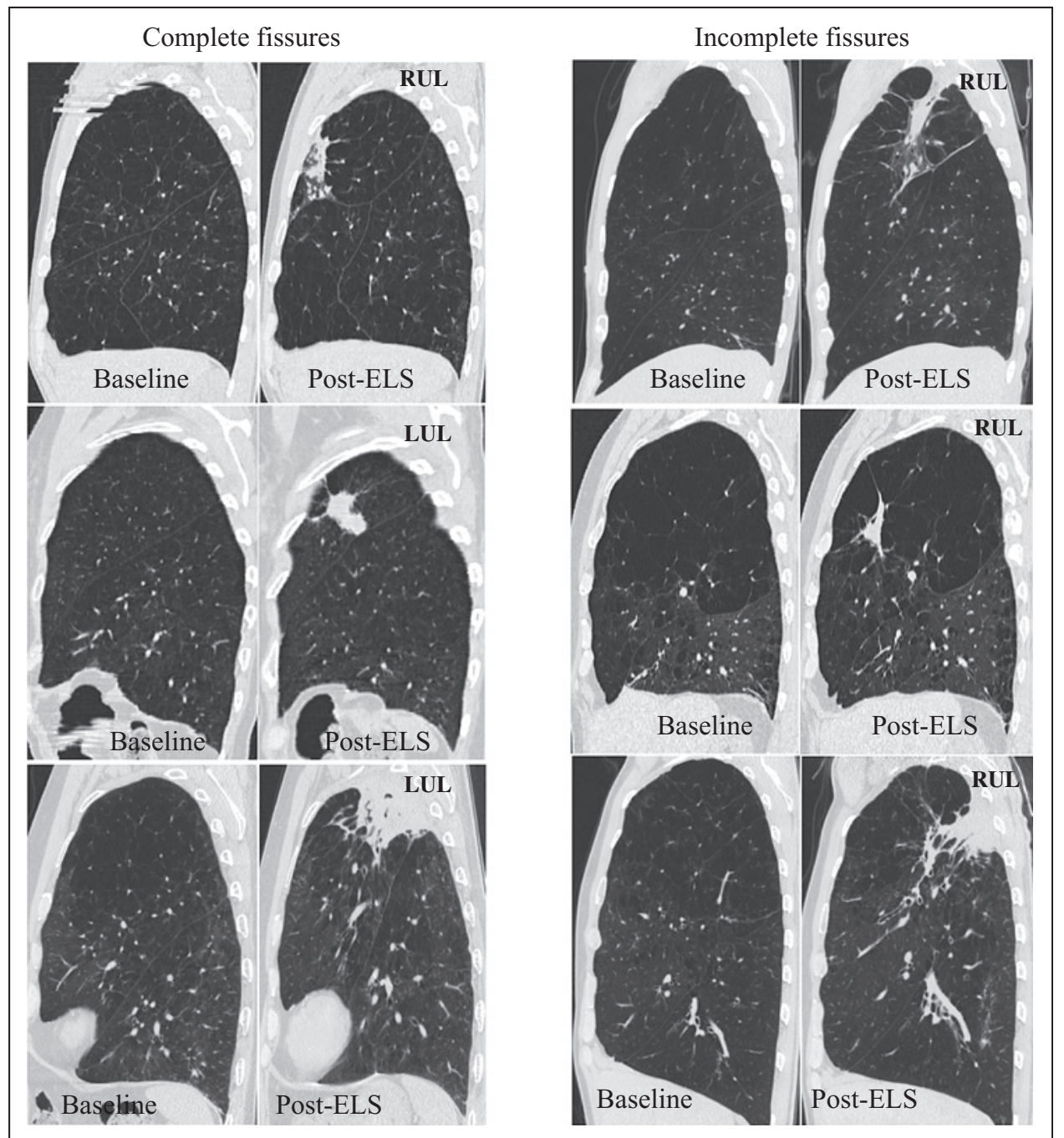

This study was not powered to detect small differences for all outcomes that might be affected by fissure status. To address this statistical limitation, multivariate stepwise regression analysis was performed to model the impact of fissure integrity on three critical outcomes: spirometry, gas trapping and CT volume reduction. The results, summarised in table 4 , show that fissure status had no effect on the ability of ELS therapy to reduce lobar volume or gas trapping, or improve spirometry. Pretreatment to post-treatment changes in $\mathrm{FEV}_{1}$, RV/TLC ratio and lobar volume each were associated with the number of treatments administered. $\triangle \mathrm{FEV}_{1}$ was also associated directly with $\mathrm{HI}$ and baseline \% predicted RV, and inversely with age. However, none of the dependent outcome measures considered in this analysis were affected by fissure integrity.

The results, summarised in table 3 and figure 1, show that ELS therapy can be highly effective in patients with CFs and those with ICFs. By contrast, results from the Endobronchial Valve for Palliation Trial (VENT) showed that patients with ICFs with upper lobe emphysema experienced minimal physiological or functional benefit from endobronchial valve therapy. ${ }^{11}$ Together these findings suggest that ELS therapy may represent a better therapeutic option for patients with upper lobe disease and ICFs, while both approaches can be considered for patients with CFs.

In summary, these results suggest that AeriSeal ELS therapy, a new generation endoscopic lung volume reduction treatment, consistently reduces lung volumes and improves pulmonary function and functional capacity in patients with advanced heterogeneous emphysema independent of fissure integrity. This article is the first to show that an endoscopic LVR technique can be broadly effective across patients with advanced ULP emphysema, independent of fissure status. Additional studies are needed to assess long-term responses to ELS therapy in patients with ICFs and CFs.

Funding Support for this study was provided by Aeris Therapeutics, Woburn, Massachusetts, USA.

\section{Competing interests None.}

Patient consent Obtained.

Ethics approval Freiberg Ethics Committee.

Contributors All authors satisfy the requirements for authorship and contributorship listed in the BMJ guidelines.

Provenance and peer review Not commissioned; externally peer reviewed.

\section{REFERENCES}

1. Asia Pacific COPD Roundtable Group. Global Initiative for Chronic Obstructive Lung Disease strategy for the diagnosis, management and prevention of chronic obstructive pulmonary disease: an Asia-Pacific perspective. Respirology 2005:10:9-17.

2. Halbert RJ, Natoli JL, Gano A, et al. Global burden of COPD: systematic review and meta-analysis. Eur Respir J 2006;28:523-32.

3. Criner GJ, Sternberg AL. National Emphysema Treatment Trial: the major outcomes of lung volume reduction surgery in severe emphysema. Proc Am Thorac Soc 2008;5:393-405 
4. Naunheim KS, Wood DE, Krasna MJ, et al; National Emphysema Treatment Trial Research Group. Predictors of operative mortality and cardiopulmonary morbidity in the National Emphysema Treatment Trial. J Thorac Cardiovasc Surg 2006:131:43-53.

5. Ingenito EP, Tsai LW. Evolving endoscopic approaches for treatment of emphysema. Semin Thorac Cardiovasc Surg 2007;19:181-9.

6. Ingenito EP, Wood DE, Utz JP. Bronchoscopic lung volume reduction in severe emphysema. Proc Am Thorac Soc 2008;5:454-60.

7. Fessler HE. Collateral ventilation, the bane of bronchoscopic volume reduction. $A m \mathrm{~J}$ Respir Crit Care Med 2005;171:423-4.

8. Herth FJ, Eberhardt $\mathrm{R}$, Ingenito $E \mathrm{P}$, et al. Assessment of a novel lung sealant for performing endoscopic volume reduction therapy in patients with advanced emphysema. Expert Rev Med Devices 2011;8:307-12.

9. Herth FJ, Gompelmann D, Ernst A, et al. Endoscopic lung volume reduction. Respiration 2010:79:5-13.

10. Gross NJ. Chronic obstructive pulmonary disease outcome measurements: what's important? What's useful? Proc Am Thorac Soc 2005:2:267-71; discussion 290-1.
11. Sciurba FC, Ernst A, Herth FJ, et al; VENT Study Research Group. A randomized study of endobronchial valves for advanced emphysema. $N$ Engl J Med 2010;363:1233-44

12. Gompelmann D. Study of Chartis System, and lack of fissure integrity assessed by CT imaging. Session 65: Presentation 373. European Respiratory Society Meeting Abstracts. 2011. www.erscongress2011.org

13. Gompelmann D. Comparison between Chartis pulmonary assessment system detection of collateral ventilation vs Core-lab CT fissure analysis for predicting atelectasis in emphysema patients treated with endobronchial valves. Session 390: Presentation 3565. European Respiratory Society Meeting Abstracts. 2011. www. erscongress2011.org

14. Herth FJ, Gompelmann D, Stanzel F, et al. Treatment of advanced emphysema with rmphysematous lung sealant (AeriSeal(R)). Respiration 2011;82:36-45.

15. Ernst A, Anantham D. Endoscopic management of emphysema. Clin Chest Med 2010;31:117-26

16. Herth FJ, Eberhard R, Gompelmann D, et al. Bronchoscopic lung volume reduction with a dedicated coil: a clinical pilot study. Ther Adv Respir Dis 2010:4:225-31.

\section{Journal club}

\section{Revisiting intrapleural fibrinolysis in empyema}

In this double-blind, double-dummy, factorial trial performed across 11 centres in the UK, tissue plasminogen activator ( $\mathrm{t}-\mathrm{PA}$ ) was used in combination with DNase in the treatment of pleural infection and compared with double placebo. Each treatment individually was also compared with the placebo group.

The primary end point measured the percentage change in area of pleural opacity seen on chest x-ray between day 1 and day 7 . The study also used the relative change in opacity, proportions of patients referred for surgery at 3 and 12 months, duration of hospital stay, pleural fluid volume drained, change in inflammatory markers, death and any adverse events as additional end points.

The combination of t-PA and DNase led to a significant reduction in lung opacity compared with placebos. Use of either t-PA or DNase alone had no significant effect. Of the secondary end points, a significant reduction in referral for surgery and hospital stay was found in the combined t-PA-DNase groups compared with placebo. However, inflammatory markers and the chance of death or adverse event were not significantly reduced in any group compared with placebo.

The findings of this trial show that a combination of t-PA and DNase significantly increases the drainage of pleural fluid in those with pleural infection while also reducing the need for surgical referral and the length of hospital stay. However, further research is needed into the risks and benefits of treatment before this combination becomes the standard treatment in the management of these patients.

- Rahman NM, Maskel NA, West A, et al. Intrapleural use of tissue plasminogen activator and DNase in pleural infection. N Engl J Med 2011;365:518-26.

\section{Andrew Fester}

Correspondence to Andrew Thomas Fester, University College London, Kamsahd, The Avenue, Sleights, Whitby, North Yorkshire Y022 5BS, UK; a.fester@ucl.ac.uk

Published Online First 20 September 2012

Thorax 2012;67:308. doi:10.1136/thoraxjnl-2011-201045 